Steve Herne, Jeff Adams, Dennis Atkinson, Paul Dash, John Jessel.

\title{
Technology, learning communities and young people: The Future Something Project.
}

\begin{abstract}
The Future Something Project (FSP), a two-year action research project, was devised to nurture the creative and technological talent of small groups of young people at risk by creating a structured network, mentored and driven by creative professionals exploring innovative ways for the two distinct target groups to work together. The project practice is located within the new field of Interaction Design and takes a social and critical approach to Art and Design pedagogy. The external research team found that one valuable way of looking at the FSP enterprise was through the social theory of communities of practice (CoPs) developed in the 1990s by Lave and Wenger (1991; Wenger, 1998). The creation of a learning community as a pedagogical strategy is central to the conception and practice of this project. This paper, therefore, sets out to apply an existing theory to a new art and design context together with more general thoughts on learning communities. It explores the potential of new technologies and different settings to effect learning within structured networks and local and virtual communities of practice.
\end{abstract}

\section{Introduction}

The Future Something Project (FSP), a two-year action research project devised and delivered by Artswork [1], aimed to develop a programme that could nurture the creative and technological talent of small groups of young people at risk. This was approached by creating a structured network, mentored and driven by creative professionals. An overall aim was to explore innovative ways for two distinct target groups to work together to be called mentors and participants. The project practice is located within the new field of Interaction Design and takes a social and critical approach to Art and Design pedagogy (Atkinson \& Dash 2005). Emerging technologies, specifically information technology, precipitate reaction and ongoing curriculum development within the field of art and design education. They may require new forms of understandings of teacher and learner identities, learning communities and situations of learning. This paper explores the complex project ecology (Harrington 1990) which brings together the themes of identities and trajectories within learning communities, new pedagogical practices and learning in different settings, through new technology and interaction design. While the details and outcomes of the project are specific there is scope for reflection on the broad themes identified above which are relevant to art and design pedagogy in both formal and informal contexts with diverse populations.

The external research team [2], brought in to make an evaluation, found that one valuable way of looking at the FSP enterprise was through the social theory of communities of practice (CoPs) developed in the 1990s by Lave and Wenger (1991; Wenger, 1998). The creation of a learning community as a pedagogical strategy is central to the conception and practice of this project and provides a conceptual model which may be of use to art and design educators reflecting on their own practice. This paper, therefore, sets out to apply an existing theory to a new art and design context together with some more general considerations on learning communities and the potential of new technologies to effect learning within structured networks and local and virtual communities of practice. 
We provide, in very brief terms, a picture of the development of learning communities before following this with more details about the Future Something community and the organisation of the programme itself. Bryce Heath (2005), Illich and Sanders (1988) and others have considered the growth of early learning communities in medieval times and have shown that these arose to meet specific social or community needs. They tended to be person-centred, task-orientated and facilitated by new technologies. In a nutshell, such communities arose as a consequence of a series of beliefs and a series of desires for social improvement.

When learning communities entered sites such as universities and other institutes, they became more formalised but they were still responding to a series of beliefs and desires for social improvement. For example, Samuel Barnet's work at Toynbee Hall in England (see Menand, 2002), influenced Jane Addam's and Helen Gates Starr's work at Hull House in Chicago which, in turn, influenced the early work of John Dewey at the University Elementary School at Chicago University on a more formalised learning community that maintained a desire for social justice and reform.

In more recent years learning communities in schools and other institutional sites in the UK have been transformed due to the effect of centralised curricula, formal assessment procedures and government inspection regimes. Here the focus is upon a desire for evidence of learning and this has transformed the entire ethos for learning and the desire to learn. In effect the modern educational project might be viewed as a marked shift from learning communities to knowledge-based communities. This is to argue that the transition from contingent learning communities towards institutionalised formal learning involves a shift from belief to knowledge, from subjects of desire to subjects of knowledge.

Today, due to the speed and reach of new technologies in many parts of the world, we are witnessing a re-emergence of communities of learning beyond institutional frameworks, coupled with a renewed theoretical interest in such communities (de Certau, 1984; Lave \&Wenger, 1991; Wenger, 1999). However such communities tend to remain underground or occluded by government structures. Such communities of learning within emerging technological contexts rely on internal relations and the ability of members to acquire outside information via the Internet. They tend to establish networks with other projects or in terms of extending their own project. For example, within art and design education, Room 13 began life as an art studio organised by pupils at Caol Primary School, Fort William, Scotland and has extended its philosophy to other centres in the UK and India (Atkinson \& Dash 2005, Harding 2005). This is an interesting development of a learning community in that it is based within a school institution but is not bound or constrained by normal institutional frameworks. The work of Tim Rollins with KOS (Kids of Survival) in New York has developed emancipatory art practices with disaffected school students moving outside the institution and has now developed to other international locations (Paley 1995, Rollins 2005). Government institutional sites of teaching and learning tend to be conservative and their response to swiftly changing socio-cultural environments tends to be reactive rather than pro-active. However, students engaged in the KOS programme were empowered to work collaboratively and produce acclaimed artworks, exploring personal and social issues with a critical perspective (ibid.). It could be argued that both KOS and FSP share a context within the tradition of critical pedagogy, to quote Rollins:

'One of my most influential philosophical and spiritual mentors, the great Paulo Freire, consistently warns educators against inventing and replicating an ossified pedagogy or teaching system that does not organically respond to the ever changing educational needs 
and social context of people and communities. In the last two decades of working with youth from distressed neighbourhoods worldwide, KOS and I are witness to the wisdom of Freire. A method in the madness of collaborative art making, a pattern in the process, has started to emerge'. (in Atkinson \& Dash, 2005, p. 5)

FSP mentors were experienced communication technology entrepreneurs or interaction designers who traditionally worked in solitude either as freelancers or in small enterprises. They would be relatively young, 21 - 35, possibly recent graduates, and/or working for commercial clients. It was anticipated that they would approach learning from their own personal enthusiasms as learners themselves within their professional or commercial environments where they had a high level of creative and technical skill. FSP participants would be young people aged 18 - 25 who may have shown latent creativity, ability, and aptitude for communication technology and digital media, but who had had little or no access to high-level training and education, or who had not been able to fully develop in traditional educational settings. Their personal circumstances might make it difficult to follow courses or commit to traditional workplaces and practices. In contrast, although close in age to the participants, the mentors were successful as informal, entrepreneurial, networked and creative professionals, adept, independent and well organised with highly developed social skills.

FSP sought to bring mentors and participants together to develop the creative and entrepreneurial skills of each. Four mentored teams were created, each of four to six young people. Echoing the iconic KOS practice a key feature was that the teams worked in locations such as an art gallery, an airport, office building or community centre chosen because they were not readily associated with mainstream education institutions such as schools or colleges. The small group size was a central element of the project model because it would enable participants to build all skill levels in supportive surroundings that differed from larger classroom environments. It ensured that each participant could receive greater individual support from the mentor in a collective environment which required a level of interpersonal communication that could be developed over the life of the project. Sharing ideas and knowledge was considered an important part of the learning process.

Participants were seen not simply as consumers of technology, but as producers responding creatively to it. FSP sought to encourage a creative response and engagement with technology via interaction design. This is a relatively new field which involves designing the behaviour of technological or environmental artefacts or systems with an emphasis on interactivity and usability, including diverse products, mobile devices, software, etc. Identified as a discipline by Bill Moggridge a British industrial designer in the 1980's, it encourages questioning and exploration of our relationship with each other and the objects and systems we create. Interaction Design is often undertaken by interdisciplinary teams and gives people the conceptual and practical tools to unpack 'givens' in everyday life and develop other possibilities and solutions.

Since technology is so prevalent in young people's lives, it has the potential to be an empowering discipline in and through, which to engage them. For instance, in the context of students with behavioural, emotional and social difficulties, recent research (Russell \& McGuigan, 2008) concluded that access to particular forms of ICT and involvement in activities that tapped into their personal interests, resulted in students who had been turned off learning becoming engaged, producing 'professional' results and showing pride in presenting to diverse audiences. In another report (Underwood, J. et al 2007) teachers' perceptions strongly associated ICT with the personalised learning agenda, the development of 'e-maturity' and the use of virtual learning environments (VLEs). In terms of policy, the 
DfES strategic approach for ICT (DfES 2005) included the themes of 'transform[ing] teaching and learning' and engaging 'hard-to-reach’ learners. Ros Hall's work $(2000,2007)$ with gay and lesbian artists and students has demonstrated how digital media and the internet, can provide a safe and socially inclusive space, for the exploration of identity and difference both within and outside formal educational contexts.

Developing ideas for the future would focus the direction each team took and would provide a concrete goal around which the many different layers of learning could be cultivated. At the outset of the project key aims were established. These included generating and developing the mentor's skills as educators, and as artists/innovators in their own right together with the participant's skills as artists, designers, and entrepreneurs, and improving their basic skills through involvement in the project. The project would explore methods of group working with tools and practices which traditionally require one-to-one relationships (human and computer, artist as solitary practitioner).

Funded by NESTA, FSP set out to develop a new form of learning community, distant from formal mainstream educational models, which explored the hybridity between what might be traditionally seen as a youth work 'training course' and an extended 'project'. It opened up the possibility of the simulation of professional practice and a more fluid conception of teaching and learning identities shared between mentors and participants in contrast to a hierarchical traditional teacher - student model. Wenger (1998) identifies the building of identity as negotiating the meanings of our experience of membership in social communities. If building identity is a practice of mutual constitution, who we are is generated through doing what we do in interaction with others. The informal and activity-based nature of the project supported a collaborative ethos between mentors and participants where rigid hierarchies and the expression of overt, single direction power relations were avoided.

\section{Creative Programme}

The project manager and four lead mentors collaborated closely on planning out a nine month creative programme of project activity. The principles of planning centred around developing team-working, levels of confidence, and creative and technical skills. The mentors could draw on extensive experience of the design industry and the way it is taught as a discipline. The creative programme set out five key modules that would take the teams through the stages of the design process, Research and Idea development, Prototyping, Marketing, Final Project and Presentation with a series of one-day workshops scheduled for the first six week period of the programme focussing on playful explorations of the different themes and tools that the FSP creative programme would explore. These included Web Design - a two-week web design brief asking the participants to design the FSP website to facilitate specific understanding and skill development in this area - as a 'live' brief participants could immediately see their work in use and develop some understanding of working for a 'client'. The programme concluded with an overseas residential to Barcelona.

\section{Workshops}

The young people worked in small teams of around four together with a mentor in their respective workshops. The workshops allowed a wide range of skills and information to be introduced and understood through practice in a modular creative programme. The mentors' professional background was greatly appreciated - in the words of one young person:

'It's nice being interactive with people who are already in the industry because they've got real world experience and it's nice to speak about that.' 
A further characteristic of the activities was that they were closely related to and often drew inspiration from their immediate surroundings in an art gallery, airport, office building and a community centre:

'...so, for example, the guys in Chichester might do something about their gallery, the guys in Worthing probably going to do something about the sea front, we're obviously going to do the airport' (Crawley mentor)

The workshop location was often used as a stimulus for ideas that were developed as part of an interactive design and had a bearing on the range of activities that took place. With the airport setting, for example, its many features such as the design, operation and the flow of passengers became regular topics for analysis and critical discussion.

Although each group of young people together with their respective mentor spent most of the time in their own particular workshop, visits to the other workshops by participants and mentors occurred regularly allowing mentors to use each other's skills. External visiting mentors provided further specialist skills (for example, in electronics, certain programming languages and print design) and, in addition to being a valuable resource in terms of content, provided inspiration and showed different ways of motivating and working, so allowing more ambitious final projects to be realised.

The space available within each workshop was minimal; enough for one or two tables for computing equipment and other materials together with seating and a lockable metal cupboard for storage. Computers, a mixture of laptop and desktop machines, together with a variety of small electronic artefacts dominated the working space. Most of the workshop activities and discussion took place around the equipment while it was running. Books and notepaper were less evident: in general it would be fair to say that the young people tended to talk, listen and do, rather than make notes.

\section{Visits to professional sites}

Visits were made to a variety of institutions such as galleries, museums and workplaces where digital media are developed or used creatively. In general there was a similarity between the work that the young people saw and their own work and in this sense the visits were regarded as having an inspirational component. Earlier on in the Project the young people visited the Institute of Contemporary Art in London where artists demonstrated how they interpreted the concept of interaction in their work and fielded questions. Later in the Project there was a visit to a graduate exhibition at the Royal College of Art. This was regarded by one mentor as 'extremely successful as it came after the students had put on their own exhibition, so they could relate to the context and challenges of exhibiting work'. A visit to the Cunning Advertising Agency provided an insight into work at a professional level as well as resulting in the young people being set a design brief leading to work that they later documented using video.

The visits provided an opportunity for the young people to experience art and design culture and 'sparked young people's interests and got them thinking about possibilities for their own projects'. According to one mentor 'These were also great bonding activities, created a good sense of identity for the group, and took the context of the project outside of its immediate geography into more exciting cities.' 


\section{Final projects, presentations and exhibition}

The teams chose to work in different ways, some developing group projects while others worked individually (Robinson 2005). Final projects included creating interactive environments, 'talking luggage', a shy robot, screen-based interactive work using 3D graphics and video, creating new electronic musical instruments, voice controlled artefacts, public art/graffiti stencil tool software and hardware, a video diary made with special effects software, a 'secretive game' and an interactive animated comic (ibid).

Presentations allowed the young people from the different workshops to meet periodically throughout the course and discuss each other's work. The mentors played a coordinating role with the young people taking a greater part as they gained experience throughout the Project. Demands were made in terms of communication skills, social performance and technical competence and the presentations took place in a range of venues that, in addition to signalling these as occasions to be taken seriously, widened the young people's experience of different institutions. The final exhibition was held in a gallery in Brighton coinciding with, and forming part of, the town's larger festival. Over the three-day period the exhibition was very well attended and provided an opportunity for the young people to take responsibility in presenting their work to a wider audience.

\section{External Research}

As stated in the introduction, the research team [2] found that one valuable way of looking at the FSP enterprise was through the social theory of communities of practice (CoPs) developed in the 1990s by Lave and Wenger (1991; Wenger, 1998). CoPs theory has been taken up particularly in management, education and in understanding virtual worlds and provides a theory of learning which acknowledges networks and groups that are informal and distributed (Barton, and Tusting 2005). It goes beyond focusing on the individual to explore the social dynamics of a learning community. This paper focuses on an analysis of the data gathered relating to this key theme that was felt to characterise the nature of Project and the development of its participants. What follows is an outline and discussion of CoPs theory. Specific episodes are then explored to illustrate revealing moments in the life of the project. Pseudonyms for the participants are used throughout.

\section{The course workshops as a 'community of practice' (CoP)}

A community of practice occurs when people jointly engage socially in a common enterprise or activity and through this learn together. Communities of practice can arise in a variety of ways, including taking part in everyday life. However, in the above respect 'community' is more than working proximity, or an organised group for a given purpose; its social fabric develops over time around things that matter so that it is possible to gain a sense of trust and belonging. Through this a community of practice develops a 'shared repertoire' of resources such as vocabulary, routines, understandings and artefacts over an extended period. Rather than being an individual pursuit or an academic exercise largely confined to the classroom, learning is 'situated' within the framework provided by the community of practice through which participation can take place. Lave and Wenger acknowledge the negotiation of meaning and the production and reproduction of knowledge inherent in the processes of communities of practice and sum them up as

.... a set of relations among persons, activity and world, over time and in relation with other tangential and overlapping communities of practice. A community of practice is an intrinsic condition for the existence of knowledge, not least because it provides the interpretative support necessary for making sense of its heritage (1991, pp. 98). 
The theory makes the assumption that engagement in social practice is the fundamental process by which we learn and so become who we are.

Taken up by business management as a model by which the development of CoPs can lead to greater productivity and synergy in a knowledge economy, literature such as 'Cultivating Communities of Practice’ (Wenger 2002) has appeared which promote the theory as a business management tool. Lea (2005), however, argues that in education the communities of practice model should be seen as a heuristic, a ways of understanding learning, rather than a 'top - down' model for tapping the benefits of CoPs in a particular context. It is important to establish that not all communities are 'communities of practice'. The three key dimensions of mutual engagement, joint enterprise, and shared repertoire are all necessary conditions for recognition in this theoretical construct (Wenger, 1998). Communities of practice are not therefore necessarily synonymous with institutional categories or organised groups. People who work alongside each other without mutual engagement cannot be said to be part of a community of practice. Membership of a community of practice is therefore elective, requires acceptance and is characterised by participation. Additionally, people can be mutually engaged across institutional boundaries developing joint enterprise and shared repertoire forming trans-institutional communities of practice. Commercial or public institutions or other social configurations as a whole are often too large or complex to be treated as single communities of practice and must therefore be regarded as 'constellations' of interconnected, or overlapping communities of practice (Wenger, 1998, pp. 126-128).

A group engaged in mutual enterprise forms a community of practice that is parallel to other communities of practice engaged in similar activities. While these parallel groups may not be united directly by mutual engagement or joint enterprise they still have much in common and share a repertoire of ways of working and language born out of their parallel enterprise. Laclau \& Mouffe's (1985) conception of discourse is not restricted to linguistic phenomena but embraces all social practices and relations. In relation to this definition, parallel communities share a wider discourse constituted by the language and shared experience of their discipline developed through practice and social interaction (Herne, 2006). Bourriaud's notion of an 'archipelago' advanced in his theorising of the Altermodern (2009), is also useful in conceptualising the relationship between parallel CoPs who share discourse and enterprise.

The Project activities occurring regularly over a period of nearly one year allowed the mentors and students to begin to develop a body of collective practices, resources and ways of interacting socially that can be regarded as a central in the development of a community of practice. The four FSP groups already linked through the internet, were brought together at various times for joint workshops, exhibitions and presentations as well as for the Barcelona residential. Barcelona was chosen as a cultural environment characterised by its art and design in addition to its architecture and although visits to cultural institutions were arranged, the schedule was a relaxed one that allowed time for the young people to explore the culture of the city in their own way. This was a central element of FSP. It formed a key tool for encouraging and observing the development of participants' interpersonal and social skills away from the confines of the teams' workshops. The programme of organised activities included a visit to Barcelona University's design department and exploratory exercises around the city. The residential had four aims: to use the experience of encounters with a different culture to inspire the participants' creative ideas and personal development; to develop the participants' confidence and skills in interpersonal communication; to encourage the participants to bond within and across the teams in informal surroundings and to provide 
opportunities for mentors to talk informally to participants about their futures and take account of this in the remainder of the course.

Bringing the groups together allowed for extended interaction between the smaller CoPs. In effect, the mentors and students in each workshop setting potentially formed parallel, closebonded learning communities where the young people engaged in technology-orientated interaction design tasks, often mirroring or simulating professional practice. At times the young people worked individually on common projects, while at other times they engaged in collaborative discussions, presentations and exchanging ideas as a fledgling 'design team' coming together with the other parallel groups in the 'archipelago' to form the larger learning community network. The interdisciplinarity of interaction design meshed well with the learning and social aims of the project as a whole.

\section{Mentors create a creative ecology}

There is no guarantee that a Community of Practice will welcome all potential members with open arms. There are barriers and boundaries to overcome. Similarly not all prospective members will necessarily wish to participate, or join the group. There are potential resistances. In a critical discussion of Wenger's ‘benign' model, Harris and Shelswell (2005) argue that issues around power, conflict, inclusion and exclusion are very much a feature of developing CoPs. In an educational context, leaders of a fledgeling CoP will need to work to make the conditions attractive and comfortable for prospective members and avoid implicit messages which might deter engagement. In the FSP project certain measures had already been taken: participants had been chosen who already had an enthusiasm for new technology and design; small group size and location diffused the potential resistance participants might harbour towards formal education and mentors were chosen who were reasonably close in age with human capital as real practitioners.

It was during the group sessions that identity play and construction were most in evidence. Mentors worked at creating a functioning design team ethos, and by implication a community of practice, in a variety of ways. Rather than adopting a traditional binary teacher/student relationship, mentors were flexible and modelled the learning or 'apprentice' role themselves when working with visiting experts. At other times they established their leading tutor identity as a source of knowledge and expertise while maintaining responsiveness to the interests and skills of the young people. They demonstrated a willingness to share ownership and negotiate the ongoing focus of the team with its members.

Superficially the workshop activity appeared to have an informal atmosphere. Beneath this, however, the mentor would play a crucial role of motivating, guiding and maintaining interest and, through this, giving the young people confidence. As one mentor reports, this was especially important in the initial stages of working with the young people in the group:

'I actually found that it was really just maintaining enthusiasm for the subjects being communicated along with patience, flexibility and preparation that carried me through.'

The importance of the mentor's role as a listener was underlined by another mentor:

'Probably the most important skill was simply in listening and encouraging the students in their ideas, this was something whose importance I had overlooked before the start of the project. In many ways I think that this was the most important part of the project - whilst the design work gave the group a focus, simply having me there regularly to talk to them and encourage their ideas was, I think, the main tangible benefit of the project for the students.' 
The technical demands made by the Project could have been quite daunting with the young people being required to build up a diverse range of skills involving computer programming, electronics and a range of design software. These demands were addressed through an overall project structure, where learning was 'situated' and determined by tasks. In the mentor's words:

'We tried to introduce skills in an ideas-driven process, rather than by medium or production role. The advantage of this was that we effectively gave exposure to a huge range of technical skills in a short period of time, presenting them as a set of tools in order to develop ideas and create prototypes.'

This pedagogical approach to embedding technical learning within real projects draws on participant's engagement and motivation in a real task in a way that can often be lost in a systematic approach to 'teaching' skills. Through task-based activities there was the potential for learning to become a fundamentally cooperative and collaborative endeavour.

Collaboration was seen as more than simply dividing up a task with the young people merely working in the same space at the same time. Collaboration involves a meeting of minds. For one mentor:

'... group work allowed collaborative features - like shared discussion and decision making but also the differentiation of roles. This differentiation was a great way of allowing young people with a range of skills and abilities to all feel challenged and engaged while not breaking the pace of the project development. If the same demands had been made of everyone, some would have lost interest, feeling out of their depth, while others would become bored because they were waiting for others to catch up'.

This gives a flavour of a genuinely emerging community where differentiated demands were made according to participant's platforms of experience and engagement in the social context of the learning community.

In his role as a mentor, one noted another important social dimension:

'I was struck by two distinct communicative features of the group work, which were fostered by the informality of the workshop structure. There was a primary conversation, which took place between the group and myself, which set and directed tasks and discussion. Parallel to this ran a secondary banter, usually between the young people but which I was also able to adopt. This banter was about outwardly checking that everyone was moving forward together. It was supportive in relation to others though frequently self-deprecating in a light way, "ah how are you doing that" and "my one is shit" etc. Initially I thought this secondary banter was disruptive, that it distracted from the direction of the workshop structure, but it became clear that it almost wholly supported it.'

Huge differences were found in verbal communication skills. Although some of the young people were good verbal communicators socially, they were less articulate when it came to discussing ideas in terms of art and design. According to his mentor, for example, $\mathrm{P}$ came across as over-confident and very articulate - but not good at keeping to topic. In response to this he was encouraged to speak less. In this way his listening skills improved along with his ability to allow others to speak in turn and to keep to topic. Another young person was good about communicating his own ideas and his own work but needed continual encouragement to contribute to ideas generated within the group. A number of the young people were found to lack confidence both with their peers and in other social settings. G was well informed, intelligent and potentially eloquent but being painfully shy often found it difficult to 
articulate his ideas or opinions. V was shy and often uncommunicative in social situations although more comfortable in a one-to-one setting.

Because learning was situated in the dynamics of the workshop group, the young people were able to demonstrated a range of degrees of engagement, one or two taking a leadership role, mediating between the group and tutor/mentors and many working with sustained concentration and involvement. Alternatively, a minority demonstrated a more peripheral engagement, evident in their attendance record, poor punctuality, body language and contribution to discussion, although their degree of involvement could be transformed by positive experiences.

One particularly telling moment was a key interchange during a 'design team simulation' session:

Mentor: 'You have to be able to constructively criticise something ... it seems you take it really personally when you are criticising ... You have to stand back from it... this could be your job in ten years time. ... There are a lot of views that I don't agree with but I have to swallow that most of the time just to get by, day to day. You have to support [the discussion].'

YP 1: 'Or you just end up destroying yourself...'

Mentor: 'You have to see difference as a virtue. You cannot immediately exclude yourself from something because it's different, because you don't agree with them. What do you think of that?' [directed towards the rest of the group]

YP 2: 'If the only track you're working on is the one you are on already, then you're never going to progress are you?'

Ostensibly the message is about de-centring and accepting diversity of opinion as a positive thing while engaged in collaborative work but the tutor also models the normally 'secret' thoughts that he has while performing his professional role. The exchange demonstrates the interaction of the community while building and supporting a subtle shared repertoire of principles for their (design) practice. The tutor takes on a powerful position/identity as an insider and sanctions mutual engagement of the students in the shared enterprise as they move on an inbound trajectory from 'legitimate peripheral participation' (Lave \& Wenger 1991) to a potentially fuller and more active identity within the group.

In this workshop observation commentary the different identity roles taken up by the group are revealed:

$M$ is demonstrating his position in the group again as the closest insider of the students. He is the most confident in addressing the whole group and will make suggestions mediating between his role as student and the authority of the leading tutor. In contrast $J$ is less verbal although engaged. He is quiet, sensitive and characteristically addresses his comments, questions etc., directly to Mentor $S$ who answers him gently, even in the group situation. $C$, the last arrival seems less socially aware, or bothered and often assumes a vacant look. He will occasionally make a joke but these do not contribute to the shared repertoire, however, they are not so far out that they are rejected. The latecomers are perhaps demonstrating their engagement and position in the group, nearer the periphery, by their late-coming. However, this also provides a barrier to their full participation once they arrive. The 'legitimacy' of all the student's participation is recognised by the tutors as this is an educational context as 
well as a simulation of a professional context, where some of the less positive behaviour would be hard to get away with.

All of the mentors reported that the residential trip to Barcelona allowed them to gain further insights and understandings of the young people:

'The residential offered a space outside the project to talk to people on a different level. For a number of the students - especially those who had not travelled much before, it provided an opportunity for them to reflect on their own situation away from the pressures of their everyday experience. A lot of the questions were very focused on what they wanted to do in their future and the fact that they were outside of their normal context probably helped them to be more open about this.'

It was pointed out that living alongside the young people during the residential week allowed an understanding of the root causes of some of their problems and a chance to argue other opinions. Similarly, for another mentor, the more social atmosphere outside of the normal working and teaching environment gave rise to talk that '... really surprised me - showing how mature most of them are and, better still, how beautifully sincere their desire to mend broken pieces (99\% caused by bad parenting) and build futures as simple as flatpacked happiness.'

The trip to Barcelona was reported as a memorable episode and found to be both insightful of another culture and a successful bonding experience. For many participants, data from support workers indicated the increase in self-confidence that FSP seems to have generated. Comments on some of the young people 'experiencing a new level of independence where they are not reliant on any benefits to survive' characterised the feedback given.

The observation of an evaluation session of the Barcelona trip illustrates that for $\mathrm{J}$ a profound change has occurred in his level of engagement and confidence. On a previous occasion the observation commentary shows his uneasiness within the group:

There are a various of levels of engagement, three students [including M] make most of the discussion and are confident enough to address the whole group. Another is engaged but quiet, another $[\mathrm{J}]$ is clearly ill at ease, nervous, bites his nails make little contribution unless asked something directly. Finally there is a student [C] who looks rather vacant who tends to fiddle with things while the discussion progresses.

It is immediately apparent [after the Barcelona trip] that there has been a dramatic change in $\mathrm{J}$. He is confident, fully engaged, and now seems 'equal' to $\mathrm{M}$ (one of the more confident students). Gone is the quiet, nervous presence. He says, while presenting:

'It was great being over there. There were problems but they didn't outnumber the good things. It was really good I was really thankful for people taking me over there'.

'Thank you whoever paid for this and took me on this as it was such a nice experience'.

\section{Conclusion}

To conclude, the inception of Future Something Project can be viewed as a new venture towards establishing a series of learning communities that reworks the desire for social improvement of early learning communities. The aims refer to individual accomplishment but, importantly, they also refer to group working and the development of group skills. Through this, work becomes a collaborative enterprise where individual skills are developed which complement rather than rival each other. Mainstream education can be seen as 
currently dominated by a quest for uniformity and independence on behalf of the individual. This contrasts with diversity and an interdependence (Greenfield et al., 2003) that can be found at the heart of many thriving communities (e.g., Romero, 2004). Lave and Wenger (1991) developed the social theory of CoPs from studies of apprenticeships and Greenfield (2003) equates interdependent conceptions of competence with an 'apprenticeship' model. In this sense the Project's organisation and activities can be regarded as having a high ecological validity in terms of the world of work. The high mentor - mentee ratio would not be tenable on a long-term basis in dedicated educational institutions as we know them. However, in the world of work they are, in effect, commonplace. In today's world of work, however, the boundaries may not be defined in terms of physical space but in virtual space. Even if there is not the critical mass to maintain it, the idea of creating a structured network has begun to take shape in the Project as it takes advantage of emerging technologies to effect learning within local groups that are able to network, share and disseminate. Although the participants in the Project have undoubtedly developed their skills, it was of course not an expectation that over the duration of one year they would have reached the same level in terms of performance and output as those in professional communities. What can be argued, however, is that the Project has made some important steps in helping young people realise their potential.

\section{Bibliography}

Atkinson, D., and Dash, P. (eds.) (2005). Social and Critical Practices in Art Education. Stoke on Trent: Trentham.

Barton, D., and Tusting, K. (2005). Beyond Communities of Practice, Language, Power and Social Context. Cambridge: Cambridge University Press.

Bourriaud, N. (2009) Altermodern: Tate Triennial. London: Tate Publishing

Bryce Heath, S (2005) Seminar presented at Kings College, London 28 February 2005.

de Certeau, M. (1984) The Practice of Everyday Life, Berkeley, London: University of California Press.

Craft, A. (2001) An analysis of research and literature on Creativity in Education, Report prepared for the Qualifications and Curriculum Authority, London QCA, (accessed 21st April 2006 http://www.ncaction.org.uk/creativity/resources.htm ).

DfES (2005). Harnessing Technology: Transforming Learning and Children's Services, DfES Publications.

Greenfield, P., Keller, H., Fuligni, A. and Maynard, A. (2003). 'Cultural Pathways through universal development', Annual Review of Psychology. 54: 461-90.

Hall, R (2000) 'Inclusion through Distinction’ The International Journal of Art \& Design Education, 19, 3: 313-324

Hall, R (2007) 'Young Queer Artists in the Classroom' The International Journal of Art \& Design Education, 26, 1: 73-88 
Harding, A. (ed) (2005) Magic Moments: Collaboration between Artists and Young People. London: Black Dog.

Harrington, D M., (1990) The Ecology of Human Creativity: A Psycological Perspective. In Runco, M., and Albert, R. (eds.) (1990) Theories of Creativity. California: Sage.

Harris , S R. \& Shelswell, N. (2005) Moving Beyond Communities of Practice in Adult Basic Education. In Barton,D., and Tusting, K. (2005). Beyond Communities of Practice, Language, Power and Social Context. Cambridge: Cambridge University Press.

Herne, S. (2006). Communities of practice in art and design and museum and gallery education. Pedagogy, culture \& Society 14(1): 1 - 17.

Illich, I. and Sanders, B. (1988) ABC The Alphabetization of the Popular Mind, London: Marion Boyars.

Laclau, E. \& Mouffe, C. (1985) Hegemony and socialist strategy, London: Verso).

Lave, J. and Wenger, E. (1991) Situated Learning: Legitimate Peripheral Participation, Cambridge: Cambridge University Press.

Lea, M R. (2005) 'Communities of Practice' in Higher Education. Useful Heuristic or Educational Model? In Barton,D., and Tusting, K. (2005). Beyond Communities of Practice, Language, Power and Social Context. Cambridge: Cambridge University Press.

Menand, L. (2002) The Metaphysical Club, London: Flamingo.

Paley, N. (1995) Finding Art's Place: Experiments in Contemporary Education and Culture. New York and London: Routledge.

Robinson, A. (2005) Future Something Project (FSP). Update Report May/June/July 05. Unpublished.

Rollins, T. (2005). In Atkinson, D., and Dash, P. (eds.) (2005). Social and Critical Practices in Art Education. Stoke on Trent: Trentham.

Rollins, T. (2005) Kids of Survival. In Harding, A. (ed) (2005) Magic Moments: Collaboration between Artists and Young People. London: Black Dog.

Romero, M. E. (2004). 'Cultural Literacy in the World of Pueblo Children', in E. Gregory, S. Long and D. Volk (eds.), Many Pathways to Literacy: Young Children Learning with Siblings, Grandparents, Peers and Communities. New York: Routledge Falmer.

Russell, T and McGuigan, L. (2008) An exploration of digital creativity used to engage and motivate 'hard-to-reach' learners in behavioural, emotional and social difficulties (BESD) schools. Coventry: BECTA (Accessed 13.03.08 http://partners.becta.org.uk/index.php?section=rh\&catcode=_re_rp_02\&rid=14761)

Underwood, J., Baguley, T., Banyard, P., Coyne, E., Farrington Flint L. and Selwood, I. (2007) Impact 2007: Personalising learning with technology. Coventry: BECTA (Accessed 13.03.08 http://partners.becta.org.uk/index.php?section=rh\&catcode=_re_rp_02\&rid=14202 
Wenger, E. (1998). Communities of Practice: Learning, Meaning and Identity, Cambridge: Cambridge University Press.

Wenger, E., McDermott, R. \& Snyder, W M (2002) A Guide to Managing Knowledge. Cultivating Communities of Practice. Boston, Massachusetts: Harvard Business School Press.

\section{Notes}

1. Artswork: see http://artswork.vm.bytemark.co.uk/projects/fsp (accessed 06/06/2010) Artswork develops and manages strategic research and development projects across the Arts Council England South East region and nationally. They initiate and manage projects working with a range of partners including youth, social and health services, arts organisations and venues. Projects cover a range of art forms including: film, photography, music and literature.

2. External Research: Linguistic anthropology Professor Shirley Brice Heath worked with Artswork during the planning phase of FSP to propose a framework for specialist assessment of the project focusing on linguistic, cognitive and attitudinal changes in the mentors and student participants involved as the project progressed. Professor Brice Heath's proposal was subsequently adapted and research undertaken by a team from the Department of Educational Studies at Goldsmiths College, University of London led by Dr. John Jessel. The aim of the Goldsmiths' team was to identify key features of the Project that could be associated with any changes found in the development of the participants in terms of verbal communication, critical thinking, realising creative ideas and learning in the context of the design activities involving new technologies. Any changes in interpersonal and social skills were also to be considered.

The data gathered by the team at Goldsmiths College were largely qualitative in nature and drew on written documentation and other sources forming the participant's and mentor's selfassessment within the main Project. The researchers collected further data through audio recorded open and semi-structured interviews, video recordings made of workshop activities and presentations supplemented with direct observation and note taking. Subject protocols of participants' reported accounts of their own actions were conducted and audio recorded. Artefacts used or produced by participants were used as a focus for discussion exploring learning and development, and audio and video recordings and photographs made.

\section{Notes on Contributors}

\section{Jeff Adams PhD}

Jeff is a Professor in the Faculty of Education and Children's Services at the University of Chester, where he is leader of the Professional Doctorate in Education programme. Jeff was formally a Reader in the Department of Education Edge Hill University. Prior to joining Edge Hill he worked at Goldsmiths, researching into art education and leading the MA Artist Teachers and Contemporary Practices Programme in collaboration with Tate Modern and the National Artist Teachers' Scheme. Before joining Goldsmiths he lectured at Liverpool John Moores University, coordinating the PGCE Art and Design course, and tutored in contemporary art history for the Open University. Jeff's earlier career was spent teaching in secondary comprehensive schools in Yorkshire and Cumbria. His research interests include art education, especially contemporary art practices in schools; documentary comics and graphic novels; web-based learning; the Artist-Teacher scheme; critical studies and art history. He is currently the Principal Editor of the International Journal of Art and Design Education (iJADE). Email: j.adams@chester.ac.uk 


\section{Dennis Atkinson PhD}

Dennis is Professor of Art in Education and is Head of the Research Centre for the Arts and Learning in the Department of Educational Studies Goldsmiths College. He taught for seventeen years in secondary school and was Head of Art for Twelve years. He was the course leader for the PGCE Art and Design Secondary Course at Goldsmiths for ten years and still contributes to this programme. He is MA tutor for modules in Visual Culture and Education, Culture, Pedagogy and Curriculum, and Contemporary Art, Identity and Education which is taught in association with Tate Modern in London. He supervises MPhil/PhD students covering a range of research fields including art and design education, discourse and power in education, learner and teacher identities and action research in education. Dennis has a particular interest in employing hermeneutic, poststructural and psychoanalytic theory to explore the formation of teacher and learner identities and practices within educational contexts. He was until recently Principal Editor of The International Journal of Art and Design Education and has published regularly in academic journals since 1991. Email: d.atkinson@gold.ac.uk

\section{Paul Dash DipAD MA MPhil PhD}

Paul is a Senior lecturer in Education and Programme Leader for MA Artist Teachers at Goldsmiths. He is also co-Director for Centre for the Arts and Learning and is an external examiner for University of Wales Institute, Cardiff. Paul has previously taught in London schools for 22 years and was employed for three years by the Institute of Education. In 202 Paul received the Peake Award for Innovation and Excellence in University Teaching. In 2003 he received the Windrush Award for Contributions to Education and in 2008 was awarded a $\mathrm{PhD}$. He was until recently a Co-Editor of The International Journal of Art \& Design Education (iJADE). Email: p.dash@gold.ac.uk

\section{Steve Herne Dip AD ATC MPhil}

Steve is a Lecturer in Art in Education at Goldsmiths College where he was formally responsible for the general, specialist and studio practice art courses within the Primary BA(Ed.) programme. He currently coordinates and teaches on the Creativity and Learning, Visual Arts and Studio Practice courses on the Education, Culture and Society (ECS) BA(Hons) programme. He also contributes to the MA Artist Teachers and Contemporary Practices. He has an MPhil in Education from London University and studied fine art at Bath Academy of Art. Formerly Curriculum Advisor for Visual Arts in Tower Hamlets, he has taught art in schools in Avon and London, as a Head of Art in two, having gained a ATC at the University of Wales. He has served as an Education Advisor to the London Arts Board, and was until recently a Co-Editor of The International Journal of Art \& Design Education (iJADE). Email: s.herne@gold.ac.uk

\section{John Jessel BSc PGCE MA PhD}

John is Head of the MPhil/PhD programme and also lectures on the Secondary PGCE, and MA programmesin the Department of Educational Studies at Goldsmiths University . In addition to graduate and postgraduate teaching, John has taught at primary and secondary level. Since writing programmes for BBC Schools he has developed an interest in the role of different technologies in learning. In particular, John's research activities have focused on the social and cognitive processes that underlie learning and development within the context of the use of digital technologies. In relation to this he has initiated a series of funded projects involving detailed observation of talking and writing that occur among individuals or groups engaged in collaborative activities. John is also interested in the practices that lead to the effective use of new technologies within institutions and where existing curricula can be both enhanced and transformed. Email: j.jessel@gold.ac.uk 